\title{
"NÃO TEMOS MUITAS PERSPECTIVAS NO ENSINO DA LÍNGUA": POLÍTICA DE LINGUAGEM E FORMAÇÃO DE PROFESSORES DE ESPANHOL NO MUNICÍPIO FRONTEIRIÇO DE FOZ DO IGUAÇU
}

\author{
Marlene Niehues Gasparin ${ }^{1}$ \\ Tatiana Pereira Carvalhal ${ }^{2}$
}

\begin{abstract}
Resumo: A proposta deste trabalho é discutir desafios para o ensino e formação de professores de espanhol no município fronteiriço de Foz do Iguaçu, a partir do campo da Política e Planejamento de Linguagem (PPL). Para tanto, fez-se uma breve revisão desse campo de pesquisa e uma discussão das políticas voltadas para o ensino de espanhol em Foz do Iguaçu. Em seguida, foram analisados relatos de docentes atuantes em escolas do município. Constatou-se que há uma divergência entre uma política nacional que desfavorece o ensino de espanhol nas escolas e um planejamento local que favorece a formação inicial e continuada de professores, apesar de se configurar um cenário local de desvalorização do ensino de espanhol nas escolas e de forte prestígio do inglês sobre o espanhol.
\end{abstract}

Palavras-chave: Política e Planejamento de Linguagem; Ensino de espanhol; Fronteira.

\section{"We do not have many perspectives in teaching the language": language policy and spanish teachers training in the border municipality of Foz do Iguaçu}

\begin{abstract}
The purpose of this paper is to discuss challenges for teaching and training Spanish teachers in the border municipality of Foz do Iguaçu, from the field of Language Policy and Planning (PPL). Therefore, made a brief review of this field of research and a discussion of policies aimed at teaching Spanish in Foz do Iguaçu was carried out. Then, reports of teachers working in schools in the city were analyzed. It was found that there is a divergence between a national policy that favors the teaching of Spanish in schools and a local planning that favors the initial and continuing training of teachers, although there is a local scenario of devaluation of Spanish language teaching in schools and of strong prestige of English over Spanish.
\end{abstract}

Keywords: Language Policy and Planning; Spanish language teaching; Border.

\footnotetext{
Universidade Estadual de Maringá (marlenegasparin@hotmail.com)

${ }^{2}$ UniversidadeFederal da Integração Latino-Americana (tatiana.carvalhal@unila.edu.br)
}

$$
\begin{array}{lll}
\text { v. } 22 \text { n. } 52 \text { p. } 298-318 \quad \text { out./dez. } 2020
\end{array}
$$




\section{INTRODUÇÃO}

Este artigo é um recorte de um Trabalho de Conclusão do Curso desenvolvido no Curso de Especialização em Ensino-Aprendizagem de Línguas Adicionais da Universidade Federal da Integração Latino-Americana. A pesquisa foi realizada em um contexto de tríplice fronteira constituída por: Argentina, Brasil e Paraguai, denominado também como um espaço trinacional e transnacional, que conecta as cidades vizinhas, sendo estas, Puerto Iguazu (Argentina), Cidade do Leste (Paraguai) e Foz do Iguaçu (Brasil). Seu processo histórico promoveu uma configuração sociocultural específica, marcada por intensa imigração e pelo trânsito entre os habitantes da região, proporcionando contatos sociais, culturais, linguísticos e econômicos, e, ainda assim, sendo caracterizada como uma fronteira territorial e, ao mesmo tempo, simbólica (BOURDIEU, 1989). Trata-se de uma região delimitada por três línguas oficiais: o português, no Brasil; o espanhol, na Argentina e no Paraguai; e o guarani, também no Paraguai, além das diversas outras línguas de imigrantes faladas na região. É importante entender que esta região é cheia de representações sociais e linguísticas constituídas por seus habitantes, compondo assim assimetrias e distintos panoramas de prestígio e uso das línguas.

A partir desse contexto, este trabalho tem como objetivo refletir sobre os desafios para o ensino e formação de professores de espanhol no município de Foz do Iguaçu, considerando o campo da Política e Planejamento de Linguagem (PPL). Para tanto, foram coletados relatos de docentes de espanhol em escolas estaduais do município que atuavam no acompanhamento dos alunos do curso de Letras - Espanhol EAD, em Foz do Iguaçu, na disciplina de Estágio Supervisionado, em 2018. Os relatos dos professores regentes em relação ao ensino e os diferentes desafios enfrentados por eles foram registrados em diário de campo. Os pontos registrados eram importantes e necessários para, posteriormente, retomar e refletir com os alunos em formação. Contudo, pensando na dimensão dos fatores que regem o ensino de espanhol, nos desafios atuais de ensino e aprendizagem e o quão necessário é discutir as políticas de ensino, propôs-se realizar uma reflexão maior que resultou em um trabalho final de especialização e, em seguida, no recorte trazido neste artigo.

Existem diversos estudos elaborados tanto acerca das línguas de/na fronteira no atual contexto educacional e social de Foz do Iguaçu (PIRES SANTOS, 2004; MELO, 2013) como do prestígio e das representações de 
línguas em escolas da região (ALBUQUERQUE e SOUSA, 2013; ESCALADA, 2015; CARVALHAL, 2016; RIBEIRO, 2017). Esses estudos são importantes, pois possibilitam compreender o panorama sociolinguístico local e, consequentemente, os fatores que agem diretamente no ensino e na formação do professor de espanhol. Contudo, são necessárias contínuas reflexões, uma vez que novos cenários político-educacionais vêm modificando o panorama do ensino de língua estrangeira no Brasil.

Este trabalho inicia-se com uma discussão do campo de estudos da Política e Planejamento de Linguagem. Em seguida, são retomadas algumas políticas existentes para o ensino e para formação de professores de espanhol, no município fronteiriço de Foz do Iguaçu. Posteriormente, são analisados os dados da pesquisa, que consistem em relatos de desafios do ensino de espanhol nesse contexto, e discutidas convergências e divergências entre as políticas em interação. Por último, tece-se as considerações finais.

\section{POLÍTICA DE LINGUAGEM, ENSINO E FORMAÇÃO DE PROFESSORES DE ESPANHOL}

Política e Planejamento de Linguagem (PPL) configura-se como um campo de pesquisa interdisciplinar nas ciências sociais e humanidades, contemplando uma complexidade de questões que envolvem linguagem e sociedade. As pesquisas nesse campo iniciaram na segunda metade do século $\mathrm{XX}$, estando voltadas para a solução de "problemas linguísticos" em cenários multilíngues e para a elaboração de políticas de linguagem nacionais, para a padronização de línguas e para o desenvolvimento de gramáticas e dicionários (Cf. FERGUSON, 1968; HAUGEN, 1966, NEUSTUPNY, 1974). Identifica-se nesses primeiros estudos não apenas uma noção de língua enquanto código, sem apagar a sua heterogeneidade, mas também a noção de que as línguas têm funções e valores. Com o avanço dos estudos no campo, muitas discussões no campo da PPL passaram a focalizar as situações de redução e perda de línguas provocadas pelo avanço das línguas coloniais e, mais recentemente, do inglês global.

A política de uso da língua funciona sempre como intervenção que transforma a experiência coletiva e individual de uma comunidade em experiência que se cristaliza num complexo sistema de símbolos linguísticos e 
extralinguísticos. Por conseguinte, a política de linguagem forma parte da história social e linguística de um povo, assim, quando se fala de um problema ou conflito linguístico, faz-se referência, certamente, não à luta entre línguas, mas sim, a grupos diferenciados por fatores socioeconômicos, étnicos e/ou socioculturais.

No âmbito da discussão do aspecto da função e do valor das línguas, diversas designações e atributos foram elaborados para classificar as línguas, tais como: majoritária, minoritária e de status especial; vernácula, padrão, clássica, artificial, dialeto, pidgin, crioula; gregária, oficial, veicular, de ensino, de religião, internacional e língua objeto de ensino (FERGUSON, 1959; STEWART, 1962), evidenciando as situações desiguais em que se relacionam as línguas (e seus falantes). Em uma análise mais recente no campo, entende-se que determinada língua, seja ela majoritária ou minoritária, possui uma importância e um valor no "mercado linguístico" que dependem de uma série de fatores em que todas têm seus valores definidos por seus usuários e respectivas comunidades de fala, a quem deve ser garantido o direito de uso" (ALTENHOFEN, 2011). Nesse sentido, os valores das línguas são definidos contextualmente e, em uma perspectiva dos direitos linguísticos, a todos deve ser dado o direito ao uso de uma língua.

Dados os aspectos de valor e uso das línguas, as políticas de linguagem atuam nos usos, nas representações e também no ensino de uma determinada língua, sendo, portanto, uma ação política e ideológica. Conforme destaca Rajagopalan (2003), a política linguística se encontra ligada às mudanças políticas de diversas comunidades linguísticas, sendo guiada por propósitos ideológicos factíveis em um dado momento histórico, diante de uma dada conjuntura de circunstâncias histórico-políticas, implementadas tanto no sentido de cima para baixo (top down), como no sentido de baixo para cima (bottom up). Nesse sentido, tratar do ensino de língua estrangeira ou segunda língua é tratar de estratégias políticas que são implantadas e organizadas por decisões ou medidas legislativas que respondem a situações linguísticas, econômicas e culturais, de um determinado momento histórico-social. Portanto, tratar do ensino e da formação de professores de língua estrangeira é tratar de política de linguagem.

Nessa perspectiva, o ensino e a formação de professores de língua estrangeira no contexto escolar estão voltados para o reconhecimento de discursos e usos linguísticos como ideológicos, históricos e socialmente 
constituídos. Uma vez que as políticas de ensino de línguas estrangeiras não são neutras e estão inseridas dentro de um sistema político e social que não se restringe somente a uma política global vinda de cima, como política oficial, devem ser também consideradas as políticas efetivadas localmente, pelos estudantes e pelo(a) professor(a). Assim, em um contexto escolar, fazem política não apenas a instituição, mas também o(a) professor(a) e os(as) estudantes, na negociação de valores da língua estudada e na participação ativa das atividades de ensino-aprendizagem.

As propostas de ensino de línguas estrangeiras no Brasil afiliam-se a tendências globais da época e a interesses político-ideológicos. Em parte, em resposta às demandas de globalização econômica, o inglês se firmou como a língua estrangeira a ser ensinada nas escolas obrigatoriamente, e cada vez mais cedo isso vem ocorrendo. Assim, no contexto nacional, o espanhol passa por momentos de ausência e presença nos currículos da educação brasileira, estando atualmente em concorrência com o ensino de inglês. Em 2005, a Lei $11.161^{3}$ definia que o ensino de espanhol, de oferta obrigatória pela escola e de matrícula facultativa para o aluno, deveria ser implantado, gradativamente, nos currículos plenos do ensino médio. Nesse momento, tal como analisa Paraquett (2006), tratou-se de uma lei que ia ao encontro dos desejos integradores com a América do Sul e de um acordo econômico com o governo espanhol, dada uma dívida em formação e capacitação de professores [de espanhol]. Houve impacto também para a formação de professores, colocando as Universidades em competição com a formação ofertada pela Espanha.

No novo cenário de 2017, a Lei $13.415^{4}$ definia que os currículos do ensino médio deveriam incluir, de forma obrigatória, o ensino do inglês, mantendo o

\footnotetext{
${ }^{3}$ BRASIL. Lei n⿳⺈ 11.161 , de 5 de agosto de 2005. Dispõe sobre o ensino da língua espanhola. Disponível em: <http://www.planalto.gov.br/ccivil_03/_Ato2004-2006/2005/Lei/L11161.htm>. Acesso em: 20 junho de 2020. ${ }_{4}^{4}$ BRASIL. Lei $\mathrm{n}^{\circ}$ 13.415, de 16 de fevereiro de 2017. Altera as Leis $\mathrm{n} \stackrel{\text { o }}{9} .394$, de 20 de dezembro de 1996 , que estabelece as diretrizes e bases da educação nacional, e 11.494, de 20 de junho 2007, que regulamenta o Fundo de Manutenção e Desenvolvimento da Educação Básica e de Valorização dos Profissionais da Educação, a Consolidação das Leis do Trabalho - CLT, aprovada pelo Decreto-Lei nº 5.452, de $1^{\circ}$ de maio de 1943 , e o Decreto-Lei no 236, de 28 de fevereiro de 1967; revoga a Lei no 11.161, de 5 de agosto de 2005; e institui a
} 
ensino do espanhol como optativo, bem como outras línguas estrangeiras, conforme disponibilidade de oferta, locais e horários dos sistemas de ensino. Nota-se que, na nova pauta político-ideológica, estava clara a escolha do inglês como a única língua estrangeira a ser ensinada. Desconsiderou-se, nesse sentido, acordos anteriores, bem como o interesse na integração do Brasil na América Latina e a importância do espanhol na comunicação global. Se o contexto de ensino de espanhol e de planejamento do plurilinguismo nas escolas apresentava dificuldades, devido à ausência de medidas para efetivar essa política, o cenário ficou ainda mais desafiador, inclusive para a área de formação de professores.

\section{ENSINO E FORMAÇÃO DE PROFESSORES DE ESPANHOL NO MUNICÍPIO DE FOZ DO IGUAÇU}

Como apresentado na introdução deste trabalho, Foz do Iguaçu é um município situado na fronteira com países que têm o espanhol como língua oficial, além disso configura-se como um cenário linguístico ainda mais complexo, por receber um grande número de imigrantes, incluindo mais recentemente refugiados sírios, haitianos e venezuelanos, e por ser um lugar turístico, pelas Cataratas do Iguaçu. Apesar disso, o ensino da língua estrangeira e a formação de professores de espanhol, tal como ocorreu no contexto nacional, vêm enfrentando constantes desafios à medida que o governo do Paraná e o município de Foz do Iguaçu vão para a fase de planejamento das políticas que prestigiam unicamente o ensino do inglês nas escolas.

Considerando que a escolha e a implantação do ensino de línguas estão também fortemente ligadas às questões geopolíticas, econômicas, sociais e culturais de uma determinada região, em Foz do Iguaçu, podem ser destacadas diversas iniciativas voltadas ao de ensino de/em espanhol. Em 2005, por exemplo,

Política de Fomento à Implementação de Escolas de Ensino Médio em Tempo Integral. Disponível em: <https://www.planalto.gov.br/ccivil 03/ ato2015-2018/2017/lei/113415.htm>. Acesso em 20 de junho de 2020. 
foi criado o Projeto Escola Intercultural Bilíngüe de Fronteira (PEIBF), com o intuito de promover o intercâmbio entre professores dos países do bloco regional Mercado Comum do Sul (Mercosul). Para além de estar em consonância com a política linguística do bloco de promoção do espanhol e do português entre os países membros, o projeto planejava uma política para a fronteira com a promoção das línguas oficiais como segunda língua na região fronteiriça, por meio de escolas bilíngues e interculturais. Como observa Pereira (2014), pela primeira vez no Brasil houve uma política linguística própria para as áreas fronteiriças, voltada para o ensino de português e de espanhol como segunda língua em áreas de fronteira, e não como língua estrangeira.

Destaca-se que a região fronteiriça não se configura como uma zona bilíngue equilibrada, em que todos os cidadãos fronteiriços são bilingues em espanhol-português, mas sim um bilinguismo desequilibrado, em que a presença do português na Argentina é maior do que a do espanhol no Brasil. Essa assimetria que configura, na região fronteiriça trinacional, o português com maior status que o espanhol, deve-se ao maior desenvolvimento socioeconômico do Brasil, em comparação com os países vizinhos. Além disso, muitas vezes se utiliza alternância de códigos com propósitos comunicativos diferentes e, frequentemente, se fala o portunhol, com mesclas e empréstimos linguísticos.

Além desse Projeto, posteriormente transformado no Programa Escolas Interculturais de Fronteira (PEIF), há ainda diversas instituições, programas e projetos que favorecem, de alguma forma, e ainda que em condições nacionais dissonantes, a formação inicial e continuada de professores de espanhol e o ensino de espanhol na fronteira. No âmbito público, destaca-se o curso de licenciatura em Letras - Português e Espanhol, ofertado pela Universidade Estadual do Oeste do Paraná (Unioeste), e o curso de licenciatura em Letras Português e Espanhol como Línguas Estrangeiras, ofertado pela Universidade Federal da Integração Latino-Americana (Unila), que, em 2017, implantou também, no âmbito da Pós-Graduação, o curso de Especialização em EnsinoAprendizagem de Línguas Adicionais. Em 2018, atendendo à demanda da Secretaria Municipal de Saúde, criou-se o projeto piloto de ensino de espanhol na rede municipal, numa parceria com o Programa de Pesquisa Linguagem, Política e Cidadania, da Universidade Federal da Integração Latino-Americana (Unila). 
Entende-se, com base nisso, que apesar das atuais legislações que desfavorecem o ensino de espanhol, há avanços em relação ao 'fazer chegar' o espanhol na comunidade escolar e à capacitação de profissionais que já atuam e de quem, ainda, irá atuar no ensino da língua. Embora, na atual conjuntura política, as novas resoluções não favoreçam projetos para o ensino de espanhol com a falta de apoio governamental e de apoio de leis municipais, existe, no entanto, a insistência por propostas significativas advindas e efetivadas nas práticas de muitos profissionais da área. Nesse cenário, surge também o movimento \#Ficaespanhol ${ }^{5}$, em resposta à reforma do ensino médio que retira a obrigatoriedade da oferta do espanhol nas escolas, tomando corpo em vários estados, inclusive no Paraná.

Com a redução do espaço de ensino de espanhol nas escolas, surge a necessidade de se pensar local e globalmente nas línguas e seus contatos para que prevaleçam as discussões, reflexões, políticas e planejamentos de linguagem, sobretudo no que tange ao bi/plurilinguismo na fronteira, viabilizando e/ou abrindo espaço para ideias e propostas que promovem diálogo e construção coletiva entre as comunidades escolares, universitárias e o contexto social mais amplo. Significa, entretanto, num primeiro passo, reconhecer e enfrentar, desde a formação de professores, os desafios que se encontram na área para que então se consiga coletivamente pensar as línguas em escolas de fronteira.

\footnotetext{
${ }^{5}$ Trata-se de um movimento de frente parlamentar que defende a permanência do ensino de espanhol no currículo das escolas públicas, tendo ganhado força sobretudo em virtude da Lei 13.415/2017 que tornou obrigatório o ensino do inglês e facultativo o ensino do espanhol e outras línguas. O movimento, iniciado em 2016 por um grupo de professores de Espanhol e alunos de Letras da Universidade Federal do Rio Grande do Sul (UFRGS) e professores do colégio de Aplicação (UFRGS), já se propagou pelos diversos estados do Brasil.
} 


\section{"NÃO TEMOS MUITAS PERSPECTIVAS NO ENSINO DA LÍNGUA": DESAFIOS PARA O ENSINO DE ESPANHOL NA FRONTEIRA IGUAÇUENSE}

Como mencionamos no início deste artigo, os dados analisados aqui consistem em excertos dos relatos de professores regentes que recebiam em suas turmas estudantes em práticas de estágio supervisionado do Curso de Letras Espanhol da UFSC na modalidade a distância. Os relatos foram coletados em diferentes escolas estaduais de Foz do Iguaçu e registrados em diário de campo. Desta forma, foram coletados relatos de professores regentes com diferentes perfis e diferentes posicionamentos e crenças a respeito do ensino de espanhol.

A concepção de língua, incluindo de seu valor e de suas funções, é o fator fundamental que direciona o trabalho do professor. A prática pedagógica é, pois, orientada por suas intuições, crenças, experiências, concepções de língua e sobre o que entende do processo de ensino e aprendizagem de língua estrangeira (BARCELOS, 2004). É mediante essa compreensão que irá organizar, planejar e aplicar suas aulas, por isso, da importância de se fazer um trabalho em conjunto, em que haja espaço para discussões e reflexões sobre o ensino buscando aprimorar e partir para atividades e práticas significativas e transformadoras.

A seguir, no excerto 1, o professor relata sobre a sua atuação e suas perspectivas acerca do ensino-aprendizagem da língua na fronteira. Este professor fazia parte do corpo docente de uma instituição de uma região mais periférica do município, do período noturno.

Excerto 1:

[...] aqui temos uma realidade muito difícil, os alunos não querem aprender, eles não ficam quietos, são indisciplinados, para eles esta disciplina não tem importância, nós aqui não temos muitas perspectivas no ensino da língua.

Em sua fala, o professor relata que os estudantes não mostram interesse na aprendizagem do espanhol, e que não contribuem com as aulas, ficando inquietos e indisciplinados. Ele justifica esse comportamento dos alunos indicando que para eles a disciplina não tem importância, o que pode ser relacionado ao menor status do espanhol na região, quando comparada à língua portuguesa. Em função 
desse interesse restrito dos alunos pela língua, o professor afirma que não existe muita perspectiva para o ensino da língua naquele espaço acadêmico.

De acordo com Soarez (2015), as crenças de alunos e professores quanto à língua, à cultura e ao ensino são maneiras de ver e perceber o mundo, que são dinâmicas, interacionais e contextuais. Podem ser reformuladas com o tempo e podem ser ressignificadas, pois são construídas socialmente, mas também de modo individual, já que são formadas a partir de experiências. Nesse sentido, os professores de língua, frente a contextos como esse, desde o momento da formação, são convidados a refletir sobre as diferentes concepções de língua e sobre a perspectiva do ensinar e aprender a língua como práticas situadas, considerando que as realidades de ensino são plurais e devem ser levadas em conta no processo.

O discurso sobre não ter perspectiva sobre a língua e o porquê do estudante não enxergar importância em estudá-la dá-se certamente também pelo silenciamento da questão fronteiriça nos materiais didáticos, nos documentos oficiais sobre o ensino de língua estrangeira e, até mesmo, nos discursos utilizados pelos professores. Essas afirmativas contribuem, de certa forma, para o não reconhecimento da diversidade social/local como trocas interculturais que existem, que circulam e são negociadas constantemente pelos sujeitos que vivem na fronteira. Ainda, ao não possibilitar aos alunos pensar criticamente sobre as diferentes instâncias relacionadas às práticas sociais, desde as questões linguísticoculturais como também as assimetrias socioeconômicas e culturais compreendendo a fronteira como complexa e de grande dinamismo social, reforça-se a sua invisibilização e deslegitimação como sendo sujeitos ativos participantes dessa construção social mais ampla.

Em outro momento e no mesmo sentido, o mesmo professor relata que:

Excerto 2:

l.... eles chegam cansados, não querem prestar atenção, eles vêm só pra se encontrar com os colegas e cumprir horário...

$\mathrm{Na}$ afirmação acima sobre o desinteresse pela aula de espanhol, nota-se uma consideração generalizadora sobre os estudantes que o professor utilizava para explicar/justificar a situação que se criava durante a aula. Importante salientar que como a aula acontecia no período noturno a maioria dos alunos dessa turma, 
trabalhava durante o dia e ia para a aula à noite, então, recorrer a esse tipo de discurso era muito frequente para justificar a pouca participação nas atividades, até mesmo pelos próprios alunos.

Em observação, notou-se que a maioria dos alunos se comportava de maneira bastante agitada, não colaborativa, porém, havia alguns alunos que realizavam as atividades propostas, mas se deixavam levar pela situação majoritária que configurava a sala de aula, onde não havia um controle sobre a turma, devido ao seguimento da aula e ao posicionamento do professor frente a essas práticas 'desinteressadas' realizadas pelos alunos, em não solicitar e instigar a colaboração efetiva na aula. Embora, na visão do professor, o fato dos alunos conversarem muito durante a aula fosse sinônimo de 'não prestar atenção', poderia ser compreendido como uma ação política de deslegitimação da política de valorização do espanhol, a qual precisaria ser enfrentada ou negociada com uma política oposta, de valorização. Nesse sentido, os estudantes são vistos como pessoas pensantes e atuantes, como uma ponte que possibilita criar um ambiente de trocas interpessoais, o qual favorece um trabalho bastante significativo, por meio de discussões sobre questões políticas, econômicas, socioculturais, identitárias e, até mesmo, sobre e usos plurilingues que envolvem o ensino da língua, potencializando os interesses dos estudantes por instrumentos que permitam desnaturalizar e questionar as relações de poder que permeiam o ensino e aprendizagem da língua em questão, tanto na escola, na região de fronteira e no país como um todo.

A continuação apresentamos o relato de outro professor, também do período noturno, de outra instituição, quem igualmente relata sua percepção em relação ao ensino de espanhol e a recepção não tão favorável pelos alunos.

Excerto 3:

[... eles não dão muito valor à língua espanhola, pois é uma língua que eles acham que sabem, na verdade é uma língua fácil de se comunicar, então eles não dão muito valor [...] a gente sabe que aprender a língua é importante, a língua ensina muitas questões de culturas, mas para eles não faz diferença.

Novamente, a desvalorização do espanhol pelos estudantes é mencionada. O que chama atenção, entretanto, é o reconhecimento de que a língua é utilizada 
pelos estudantes e que é uma língua fácil de se comunicar. Apesar desses aspectos que favoreceriam potencialmente o ensino, isso é enfraquecido pela crença de que de que por serem habitantes da fronteira e terem contato constante com o espanhol, eles têm também o domínio da língua. Na fala do professor, é "[...] uma língua que eles acham que sabem [...]”. Assim, reconhecer que o espanhol não é muito difícil de ser compreendida e que, por isso, os alunos não a legitimam como uma disciplina significativa e relevante, ressalta a importância de se fazer política de linguagem no ensino e na formação de professores.

Podemos inferir que essas crenças acerca do espanhol têm relação com os discursos equivocados do senso comum de que o espanhol é uma língua de fácil aquisição, uma língua de indistinção com o português e de que todos se entendem 'dando um jeitinho', quando, na realidade, o ensino da língua deve permitir conhecer a própria língua espanhola em sua maneira global, vasta e complexa, com suas particularidades e pluralidades de sentido e significado no mundo, oras distanciado do sentido mercantilista, de interesses econômicos e políticos (HELLER, 2017), como lhe é atribuído, quase sempre, ao inglês. E, sobretudo, como língua da região, falada no cotidiano da fronteira, constituindo as relações interpessoais, incluindo silenciamentos e empoderamentos.

Ademais, fomentar esse tipo de discurso é reforçar mais ainda uma fronteira linguística e simbólica marcada pejorativamente e camuflada nos discursos de irmandade e integração, retirando a responsabilidade das políticas estatais para o investimento ao ensino, não garantindo espaço para expansão da língua, principalmente na esfera educacional.

Em outro momento, um professor de outra instituição, do período matutino, relata que, para obter a participação dos alunos, só é possível por meio de atividade de tradução de texto.

\footnotetext{
Excerto 4:

[...l o único jeito de fazer com que fiquem quietos durante um tempo é dando textos para tradução, para entregar no dia, valendo nota, assim eles se prendem no dicionário e ficam fazendo...
}

Na fala acima, observa-se mais uma vez que o professor está buscando estratégias para a participação dos alunos na disciplina, que não está dada a priori. 
Pelo relato, o exercício de tradução, associado à nota, foi o único método que o professor encontrou para que os estudantes realizassem as atividades, mas com o pretexto principal de silenciar as conversas paralelas na sala de aula, fazendo entender que o comportamento silencioso dos alunos é mais coerente e garante uma participação mais significativa na aprendizagem, quando, na realidade, a presença das vozes dos alunos pode ser sumamente ressaltante e produtiva, já que permite uma construção de conhecimento dado em sala de aula, com trocas de experiências próprias dos alunos e do professor, como mediador. Ademais, recorrer à gramática e à tradução tem sido, muitas vezes, uma prática que precede às demais atividades quando não se contempla outros métodos que privilegiam a interação e as trocas abrangendo os saberes culturais e identitários ligados ao uso da linguagem. Afilia-se a uma concepção de língua enquanto forma e produto, com pouco (ou nenhum) estímulo a discussão de seu valor ou função, ou ainda enquanto forma de ação e construção social.

O ensino isolado da gramática ou de textos aleatórios para tradução sem relação com os possíveis contextos locais de uso da língua, ou sem considerar a experiência do estudante quanto à recepção, percepção e compreensão do texto estipulado para a aula, por um lado, configura uma forma mecânica de se ensinar a língua e, neste caso, tratando de língua estrangeira, não se torna significativa uma vez que não dá espaço para a contextualização e discussão de temas presentes no textos mas, por outro lado, não podemos desconsiderar que a prática da tradução seja interessante e positiva haja vista que existe interesse por parte dos alunos por esse tipo de exercício, neste caso, temos que olhar para a prática de tradução como um caminho para avançar na aprendizagem e no uso do espanhol, particularmente significativos, se contempladas questões socioculturais fronteiriças. Compreender o contexto de aprendizagem e visualizar estratégias de aprendizagem é, certamente, uma das tarefas docente.

A partir desses exemplos, foi possível verificar que estes professores regentes têm dificuldade de pôr em prática um ensino mais dinâmico e efetivo em virtude do desinteresse da turma pela disciplina. Nesse sentido, coloca-se em foco a necessidade de se trabalhar na formação de profissionais das Letras os desafios explicitados e a habilidade de se pensar e fazer política de linguagem localmente, tratando também de como nós, professores de línguas, agimos e colocamos em práticas nossas concepções de ensino-aprendizagem. Essas percepções sobre língua e ensino é que, muitas vezes, direcionam o trabalho do 
profissional e que reflete em sala de aula, nas práticas dos alunos e, por conseguinte, na comunidade de forma mais ampla.

Reconhecer e valorizar no ensino que línguas minorizadas tenham um significado social é um desafio de todos os profissionais, desafio que atenta para o impacto do efeito da globalização em relação às dinâmicas das relações e interações sociais. Então, é cabível sermos menos consumidores passivos das políticas homogeneizadoras e mais condutores ativos de políticas significativas e de mudanças sociais, dando ouvido à diversidade linguística e cultural do nosso entorno, investindo em projetos de conscientização linguística para a integração nacional e internacional.

Ainda, parece existir um grande desafio para os profissionais da área do ensino de espanhol em escolas, em aplicar e enxergar uma perspectiva significativa no ensino-aprendizagem da língua, tendo em vista posicionamentos e políticas divergentes, desde a esfera político-pedagógico, bem como da realidade local onde muitos dos profissionais atuam. É necessário haver mudanças sociais por meio do campo educacional e ensino de línguas que contribuam para a formação de alunos-cidadãos à luz de uma proposta com valor educacional, numa sociedade em que existe a necessidade que prevaleça "a pluralidade, a diferença, o estrangeiro, o outro” (MONTE MÓR, 2012, p. 38), evidenciado pelas dinâmicas sociais em busca de maior integração.

\section{A (INTER)AÇÃO DAS POLÍTICAS DE LINGUAGEM PARA O ENSINO DE ESPANHOL EM FOZ DO IGUAÇU}

Nas seções anteriores foram discutidos alguns desafios para o ensino de espanhol a partir dos posicionamentos dos professores frente às realidades do ensino e aprendizagem da língua em escolas locais. Nesta seção, serão discutidos outros desafios a partir da interação das políticas e dos planejamentos para o ensino da língua e formação de professores. Em primeiro lugar, identificamos que existe uma divergência entre uma política nacional que desfavorece o ensino de espanhol nas escolas e um planejamento local que favorece a formação inicial e continuada de professores em Foz do Iguaçu. Enquanto município fronteiriço, a ausência de políticas de linguagem para as escolas de fronteira é, de certa forma, fator que gera essa divergência. 
Nesse sentido, as formulações sobre o ensino de espanhol apresentadas pelos professores regentes são construções que, muitas vezes, evidenciam a necessidade de maior articulação das políticas de línguas entre instâncias oficiais/legitimadoras e os sujeitos efetivamente envolvidos. Para isso, cabe salvaguardar uma política de linguagem plurilíngue para a educação nas escolas de fronteira, desde uma instância maior, como regulamentos estatais/nacionais fazendo relação com práticas e políticas locais, onde existem dinâmicas e confrontos linguísticos pelos quais veiculam diferentes construções de identidades e a necessidade do reconhecimento e do viver interculturalmente, por meio do ensino e aprendizagem de línguas estrangeiras/segunda língua.

Em segundo lugar, há um cenário local de desvalorização do espanhol não condizente com o status internacional da língua e com o contexto fronteiriço. É importante destacar que, por um lado, a inserção do espanhol no sistema de ensino vem, gradativamente, enfrentando um caminho contrário às tendências que em outros momentos foram favoráveis a sua implementação, como na implementação do Projeto Escola Intercultural Bilíngüe de Fronteira (PEIBF), e isso, de certa maneira, influencia diretamente o enfraquecimento do status da língua no cenário escolar e social, como língua internacional e língua de grande circulação, uma vez que não condiz com as tendências das políticas hegemônicas e oficiais, que reforçam o papel de língua internacional apenas ao inglês. Por outro lado, configura-se um status mais baixo do espanhol na fronteira, neste caso, no município de Foz do Iguaçu, o que não deixa de ser um paradoxo, uma vez que, é justamente neste contexto que deveria haver maior interesse e integração social por meio da língua.

É importante também considerar que o ensino de espanhol deve estar pautado nas relações sociais de políticas de linguagem nacionais e locais, em que os sujeitos fronteiriços se constroem e se reconstroem socialmente por meio da língua, e reconhecer o espanhol como prática legítima da fronteira, como instrumento de comunicação, de negócio, de identidade, de cultura, favorecendo uma formação de postura crítica em relação a heterogeneidade linguística e à formação intercultural. Na função de professor formador, frente a divergentes situações problemáticas no contexto educacional, compete-nos facilitar ao aluno, por meio da língua, o acesso à cultura, à ciência, à formação cidadã crítica, a saber refletir sobre suas próprias práticas de linguagens etc., considerando que todos 
são sujeitos atuantes no processo do ensinar e aprender e, assim, conscientizá-los e despertar neles a tarefa da busca pelo aprendizado.

Em terceiro lugar, é perceptível um cenário nacional e local de forte prestígio do inglês sobre o espanhol, refletido nas políticas de ensino de língua estrangeira nos currículos escolares. Apesar dos esforços no âmbito acadêmico, ainda se carece de promover e consolidar políticas de línguas que permitam avançar para uma sociedade de caráter plurilíngue que supere o olhar monolítico e hegemônico. Ainda se mantém e se naturaliza a percepção de monolinguismo no Brasil e, quanto à língua estrangeira, se reconhece o inglês, mais que as demais línguas, como língua internacional e língua a ser aprendida. Fazendo isso, seguese contribuindo com as políticas hegemônicas que afetam o reconhecimento, a valorização e a promoção das diversidades linguísticas locais.

Entende-se ainda que o reconhecimento e legitimação da diversidade como práticas sociais diversas movidas por relações de poder são necessárias nas escolas como forma de criar um espaço 'culturalmente-sensível', tal como propõe Bortoni-Ricardo (2007). É clara a importância de reconhecer, visibilizar e legitimar a diversidade linguística cultural dentro das escolas, mas pode haver conflitos se as políticas públicas educativas e os cursos de formação de professores não prepararem adequadamente estes profissionais de línguas para o contexto de pluralidades que gere um trabalho intercultural (TALLEI e SALGADO, 2018). Nesse sentido, projetos de formação inicial e continuada precisam contemplar as particularidades do contexto fronteiriço, de modo a enxergar o contexto heterogêneo e as relações de poder que atravessam as salas de aula e poder promover o uso da língua como prática social real e significativa.

\section{CONSIDERAÇÕES FINAIS}

Neste trabalho, buscou-se refletir sobre os desafios para o ensino e formação de professores de espanhol em Foz do Iguaçu, considerando as políticas de linguagem que (inter)agem no município e os discursos de docentes atuantes no ensino da língua em colégios estaduais do município. Constatamos que há uma divergência entre uma política nacional que desfavorece o ensino de espanhol nas escolas e um planejamento local que favorece a formação inicial e continuada de professores, apesar de se configurar um cenário local de 
desvalorização do ensino de espanhol nas escolas e de forte prestígio do inglês sobre o espanhol, refletido nas políticas de ensino de língua estrangeira nos currículos escolares. Nessa interação de políticas e planejamentos de linguagem para a região, os professores relatam o desafio de lidar com o desinteresse dos estudantes pela disciplina de espanhol e a necessidade de se recorrer a propostas de ensino que eles mesmos não consideram tão adequadas.

Nesse cenário, destaca-se certamente a mobilização política dos professores em escala nacional e regional voltada para a valorização do ensino do espanhol. Contudo, em vista do cenário de retrocesso enfrentado, com a retirada do ensino do espanhol como disciplina de oferta obrigatória, é ainda necessário ampliar diferentes formas e propostas de políticas linguísticas locais que objetivam a promoção do espanhol como língua da fronteira.

Acreditar que o ensino do espanhol venha a fazer parte do currículo e do dia a dia da realidade escolar é e deve ser uma vontade de nós, professores de línguas, particularmente das regiões de fronteira. Entretanto, tal como nos lembra Maciel (2012), o currículo precisa ser feito em sala de aula, com ações e práticas significativas, para que haja não só um currículo escrito, mas principalmente, um currículo ativo dentro de uma perspectiva reflexivo crítica nas práxis educativa. Trabalhar com a língua é se inserir na dinâmica de formação social, na criação do senso de cidadania e no fomento da sensibilidade com a diversidade linguística e cultural, compreendendo o outro e a si mesmo como um agente e protagonista social, criando e vivendo uma relação de identidade e alteridade, no qual os valores globais possas ser interpretados localmente (MONTE MÓR, 2012, p. $40)$.

Por fim, formular estratégias educacionais que promovam o bi/plurilinguismo, o reconhecimento e a valorização da pluralidade linguísticocultural configura-se como um direcionamento para as políticas e planejamentos de linguagem na contemporaneidade, particularmente em regiões de fronteira marcadas por relações históricas de contato-conflito. Estudos como este, que analisam a interação de diversas políticas e planejamentos de linguagem, ajudam a interpretar cenários linguísticos, bem como a redirecionar e replanejar as políticas para que se consiga avançar nos projetos, sobretudo localmente. 


\section{REFERÊNCIAS}

ALBUQUERQUE, José.; SOUSA, Flavia. Escolas de Fronteira: percebendo diferenças, construindo pontes. 29를 Reunião Brasileira de Antropologia, 2013.

ALTENHOFEN, Cléo.; BROCH, Karen. Fundamentos para uma "pedagogia do plurilinguismo" baseada no modelo de consciência linguística (language awareness). V Encuentro Internacional de Investigadores de Políticas Linguísticas, Montevideo/Uruguay, 2011.

AMATO, Laura. Interculturalidade e língua: uma experiência em uma Escola Municipal de Foz do Iguaçu. In: SOUZA, F. M., and ARANHA, S. D. G., orgs. Interculturalidade, linguagens e formação de professores [online]. Campina Grande: EDUEPB, 2016.

BARCELOS, Ana Maria. Crenças sobre aprendizagem de línguas, linguística aplicada e ensino de línguas. Linguagem \& Ensino, Pelotas, v. 7, n. 1, p. 123-156, 2004 .

BRASIL. Lei no ${ }^{\circ} 1.161$, de 5 de agosto de 2005. Dispõe sobre o ensino da língua espanhola. Disponível em: <http://www.planalto.gov.br/ccivil_03/_Ato20042006/2005/Lei/L11161.htm>. Acesso em: 20 junho de 2020.

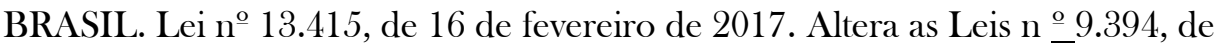
20 de dezembro de 1996, que estabelece as diretrizes e bases da educação nacional, e 11.494, de 20 de junho 2007, que regulamenta o Fundo de Manutenção e Desenvolvimento da Educação Básica e de Valorização dos Profissionais da Educação, a Consolidação das Leis do Trabalho - CLT, aprovada pelo Decreto-Lei no 5.452, de $1^{\circ}$ de maio de 1943, e o Decreto-Lei no 236, de 28 de fevereiro de 1967; revoga a Lei no 11.161 , de 5 de agosto de 2005; e institui a Política de Fomento à Implementação de Escolas de Ensino Médio em Tempo Integral. Disponível em: <https://www.planalto.gov.br/ccivil_03/_ato20152018/2017/lei/113415.htm>. Acesso em: 20 de junho de 2020. 
BORTONI-RICARDO, Stella Maris (orgs.). Transculturalidade, linguagem e educação. Campinas - SP: Mercado de Letras, 2007.

BOURDIEU, Pierre. A identidade e a representação. Elementos para uma reflexão crítica sobre a ideia de região. In. O poder simbólico. Lisboa: DIFEL, Rio de Janeiro: Bertrand Brasil, 1989.

CARVALHAL, Tatiana. Conflitos linguísticos em zonas fronteiriças: diagnóstico das atitudes linguísticas e do perfil sociolinguístico dos estudantes de uma escola de Foz do Iguaçu. In: Seminário Ibero-americano de Diversidade Linguística, 2016, Foz do Iguaçu. Anais do Seminário Ibero-americano de Diversidade Linguística. Brasília, DF: Iphan, 2016.

ESCALADA, Adriana. O ensino de espanhol na tríplice fronteira: encontros e desencontros nas representações de professores e alunos. 2015. 84 f. Dissertação (Mestrado em Sociedade, Cultura e Fronteiras) - Universidade Estadual do Oeste do Paraná, Foz do Iguaçu, 2015.

FERGUSON, C. A. Diglossia, Word 15, 1959, p. 325-340.

FERGUSON, Charles A. Language development. In: FISHMAN, Joshua A.; FISHMAN, Charles A.; FERGUSON; DAS GUPTA, J.(eds.) Language Problems of Developing Nations. New York: John Wiley \& Sons, 1968, p. 2735.

GONZÁLEZ, Neide. A importância da formação inicial e continuada na atual conjuntura da implantação do ensino de espanhol nas escolas brasileiras. In: Elzimar Goettenauer de Marins Costa; Cristiano Silva de Barros. (Org.). Se hace camino al andar: reflexiones em torno do ensino de espanhol na escola. 1ed. Belo Horizonte: UFMG, 2012, v. 1.

HAUGEN, Einar. Linguistics and language planning. In: BRIGHT, W. (Ed.). Sociolinguistics. The Hague: Mouton, 1966, p. 50-71.

HELLER, Monica e McELHINNY, Bonnie. Language, Capitalism, Colonialism: Towards a Critical History. Toronto, University of Toronto Press, 2017. 
MACIEL, Daniela. A língua espanhola no currículo das escolas públicas. XVI ENDIPE - Encontro Nacional de Didática e Práticas de Ensino - UNICAMP Campinas - 2012.

MELO, Thiago. Narrativas educacionais em perspectiva: línguas e culturas no contexto escolar de fronteira. 39 páginas. Orientadora: Maria Fatima Menegazzo Nicodem. Monografia de Especialização em Educação: Métodos e Técnicas de Ensino. Universidade Tecnológica Federal do Paraná, Medianeira, 2013.

MONTE MÓR, Walkyria. O ensino de línguas estrangeiras e a perspectiva dos letramentos. In: Elzimar Goettenauer de Marins Costa; Cristiano Silva de Barros. (Org.). Se hace camino al andar: reflexiones em torno do ensino de espanhol na escola. 1ed. Belo Horizonte: UFMG, 2012, v. 1.

NEUSTUPNY, J. V. Basic types of treatment of language problems. In: FISHMAN, J. (Org.). Advances in language planning. The Hague: Mouton. 1974, p. 37-48.

PARAQUETT, Márcia. As dimensões políticas sobre o ensino da língua espanhola no Brasil: tradições e inovações. In: MOTA, Kátia e SCHEYERL, Denise (Orgs.) Espaços lingüísticos: resistências e expansões. Salvador: EDUFBA, 2006, p. 115-146.

PEREIRA, Stella Maris Meira da Veiga. Programa de escolas interculturais bilíngues de fronteira: integração e identidade fronteiriça. Dissertação (Mestrado) - Universidade Federal de Santa Catarina, Centro de Filosofia e Ciências Humanas. Programa de Pós-Graduação em Geografia. Florianópolis, SC, 2014.

PIRES SANTOS, Maria Elena. O cenário multilíngue/multidialetal/multicultural de fronteira e o processo identitário "brasiguaio" na escola e no entorno social. 2004. 253 f. Dissertação (Mestrado em Linguística Aplicada) - Universidade Estadual de Campinas, Campinas, 2004.

RAJAGOPALAN, Kanavillil. Por uma linguística crítica: linguagem, identidade e a questão ética. - São Paulo: Parábola editorial, 2003.

RIBEIRO, Simone. Políticas linguísticas e ensino de língua(s) de fronteira na escola. Revista Organon. v. 32, n. 62, junho de 2017. 
STEWART, W.A. An outline of linguistic typology for describing multilingualism. In: RICE, F. A. Study of the role of second languages in Asia, Africa and Latin America. Washington, D. C.: Center for Applied Linguistics of the Modern Language Association of America, 1962, p. 15-25.

SOAREZ. Ana Carolina. Aprender e ensinar espanhol como língua estrangeira: o papel das crenças na formação de ingressantes no curso de licenciatura em letras. Dissertação (Mestrado) -- Universidade Federal de São Carlos, 2015.

TALLEI, Jorgelina; SALGADO, D. Escuelas interculturales en Foz do Iguaçu: universidades públicas, territorio y saberes docentes. In: Miranda, Cícero. (Org.). La lengua española en Brasil Enseñanza, formación de profesores y resistencia. 1ed.: SECRETARÍA GENERAL TÉCNICA, 2018, v. 1, p. 130-139.

Recebido em 13 de junho de 2020

Aprovado em 28 de agosto de 2020 